\title{
LEXICOGRAFÍA ACADÉMICA Y LEXICOGRAFÍA DIDÁCTICA: ¿RELACIONES EXCLUYENTES O CONCEPTOS COMPLEMENTARIOS?
}

Es muy probable que, si se le preguntara a un hablante competente por la característica que debería poseer su diccionario, la respuesta sería, antes que ninguna otra (capacidad codificadora o que contuviese algún tipo de información especial), que el repertorio en cuestión contase con el respaldo "académico" y que la norma que representara fuera la "oficial”. Sin embargo, al ser cuestionado sobre qué entiende por eso de ser "académico" y "oficial”, difícilmente podría dar una respuesta clara y convincente, porque, como veremos, la posesión de estos rasgos en lexicografía es una cuestión no exenta de polémica.

Estas características de lo académico y lo oficial están vinculadas, por supuesto, al prestigio que siempre se le otorgó a la lexicografía académica, que cuenta con un referente que pocos cuestionan: el Diccionario de la lengua española (DRAE), si bien, en el ámbito especializado se sabe que esa herencia de prestigio y autoridad del DRAE le viene de su precedente, el conocido como Diccionario de Autoridades (1726-1739), repertorio que muy pronto, por razones también conocidas, fue despojado de muchas de las características que lo hacían una obra ejemplar para convertirse en un compendio que, a pesar de todo, viene ostentando la condición de ser el diccionario más representativo en sus más de dos siglos de existencia. Por esta razón, el $D R A E$ se ha convertido en el centro de la lexicografía española y se le considera la referencia para la valoración de cualquier repertorio lexicográfico, de modo que un diccionario se juzgará más o menos prototípico en la medida en que su contenido - macro y microestructural- se adecue más o menos a la edición del $D R A E$ vigente en cada momento. La consideración que se le atribuye a este diccionario es tal que se le otorga el crédito de ser el "diccionario oficial", por más que nadie, ningún organismo público ni académico, le hubiera concedido en algún momento ese rango. Sin embargo, no se puede negar el prestigio y la autoridad que se le reconoce, siempre atribuidos por la 
sociedad y no impuestos ni asumidos por la Real Academia Española. Manuel Seco resume muy bien esta circunstancia:

Es innegable el prestigio del Diccionario de la Academia entre la generalidad de los hablantes de español, incluidos los hispanoamericanos. El Diccionario es reconocido como la voz de la Academia, y la Academia es considerada como el oráculo del idioma, como la máxima autoridad indiscutible. Sin embargo, esta autoridad es en cierto modo, al menos en su origen, involuntaria. Quiero decir que no sería exacto hablar de una asunción de autoridad lingüística por la Academia, sino de una atribución de tal autoridad por parte de la sociedad. La historia de esa atribución empieza por la excelencia de la primera obra académica, el Diccionario de autoridades... ${ }^{1}$.

LO ACADÉMICO Y LO DIDÁCTICO

EN LA LEXICOGRAFÍA ACADÉMICA

\section{Lo académico}

Por muchas razones conviene precisar este concepto de "lo académico" en lexicografía, pues suele valorarse esta característica por encima de otras más ajustadas a los fines de la disciplina, como la que debería ser la principal: la adecuación del diccionario a sus destinatarios; correspondencia necesaria entre destinatario y usuario en pocas ocasiones conseguida, pero atenuada en algunos casos, como el del $D R A E$, por tratarse de un repertorio que disfruta de la "discutida" autoridad académica.

El adjetivo "académico" cuando se utiliza en lexicografía y se aplica a un diccionario presenta la ambigüedad que se deriva de la propia polisemia de este adjetivo. Un diccionario puede considerarse académico si está elaborado por la Real Academia Española (acepciones $1^{\mathrm{a}}$ y $2^{\text {a }}$ del $D R A E$ ) y, desde este punto de vista, serían diccionarios académicos, además del DRAE, el Diccionario manual e ilustrado de la lengua española (RAE, 1927, $1^{\mathrm{a}}$ ed.); el Diccionario esencial de la lengua española (RAE, 2006); el Diccionario escolar de la lengua española (RAE, 1996, $1^{\mathrm{a}}$ ed.); el Diccionario del estudiante (RAE, 2005, $1^{\mathrm{a}}$ ed.); el Diccionario práctico del estudiante (RAE-ASALE, 2007, $1^{\mathrm{a}}$ ed.); el Diccionario esencial de la lengua española (RAE, 2006); el Diccionario panhispánico de dudas (RAE-ASALE, 2005), y el Diccionario de americanismos (ASALE, 2010).

1 "La lexicografía del español en el fin de siglo", en Estudios de lexicografía española, Gredos, Madrid, 2003, pp. 401-402 (publicado en Donaire, London, marzo de 1995, núm. 4, pp. 67-75). 
Todos han sido elaborados por la real Institución y, en algunos casos, además, con la colaboración de la Asociación de Academias de la Lengua Española (ASALE). Pero también podríamos aplicar este adjetivo a un repertorio que hubiera sido elaborado ajustándose a pautas tradicionales de corrección o propiedad ( $5^{\mathrm{a}}$ acepción del DRAE); y, según este sentido, habría diccionarios que serían académicos sin que la Academia hubiera tomado parte en su elaboración. El problema se complica cuando reconocemos que en muchas ocasiones se usa este adjetivo para individualizar a uno de los diccionarios elaborados en el seno de la Academia; así, se considera que es el DRAE "el diccionario académico" por antonomasia, o, utilizado el sintagma en plural, "los diccionarios académicos", para hacer referencia a las, por ahora, veintitrés ediciones de este diccionario, cuya denominación, por cierto, convendría fijar de una vez². Nadie reconocería como "el diccionario académico" al Diccionario del estudiante, ni al Diccionario panhispánico de dudas o al Diccionario de americanismos, consideradas estas obras de manera individual.

En cualquier caso, lo cierto es que hasta hace bien poco este carácter de "académico", es decir, de parecerse a las obras académicas o de recoger su contenido, total o parcialmente, constituía una marca de calidad que incluso utilizaban empresas editoriales para ser exhibida a efectos comerciales o publicitarios, aunque el producto resultante no fuese el adecuado -como solía ser- para tal o cual grupo de usuarios. Así, cuando hubo autores o editores que "se aventuraron" a elaborar compendios del DRAE apelando a sugerencias de la propia Institución formuladas en sus Estatutos, la técnica utilizada fue la de la copia literal, pues la reproducción del modelo, aunque fuese parcial, garantizaba el contenido académico de los repertorios. Ejemplos de esta práctica hubo muchos y, como se desprendía de sus títulos y

${ }^{2}$ El Diccionario de la lengua española de la Real Academia, conocido por el acrónimo DRAE, recibe diversas denominaciones en los propios prefacios, advertencias y en otros textos académicos: diccionario general, diccionario de uso, diccionario usual, diccionario común, diccionario vulgar, el diccionario grande, el diccionario por excelencia, etc., y esta variedad de nombres puede llevar a erróneas interpretaciones, toda vez que la teoría lexicográfica ha ido fijando algunos de estos sintagmas para identificar diferentes tipos de diccionarios que no siempre coinciden con el modelo que todos asociamos con el Diccionario académico, como pueden serlo el de diccionario general, diccionario usual (o de uso), o incluso el de diccionario vulgar. El DRAE no es un diccionario general en sentido estricto, pues registra muchas voces y acepciones particulares o específicas de muchos dialectos del español (sí lo es en tanto que se opone a los diccionarios especiales o técnicos); tampoco es un diccionario usual o de uso, concepto que se asocia más con el de "diccionario manual"; y pocos relacionarían hoy un diccionario calificado como vulgar con un diccionario común, pues se siente más próximo este adjetivo con los sentidos de 'grosero' o 'soez', valores cercanos al ámbito lingüístico de los denominados diccionarios de vulgarismos. Bueno sería, pues, que se fijase una denominación para evitar estas ambigüedades y equívocos. 
de sus prólogos ${ }^{3}$, aspiraban a convertirse en diccionarios didácticos, aunque, como se ha dicho, su adecuación a los potenciales destinatarios escolares era inexistente.

Manuel Seco reflexiona sobre esta idea de "lo académico", y considera que la "garantía académica" sólo la posee el $D R A E^{4}$; el resto de los diccionarios puede compartirla en la medida en que presentan contenidos en común con el Diccionario académico. De este modo, cuando en su estudio crítico del Diccionario manual e ilustrado de la lengua española (1927) de la Real Academia se refiere a las claves del éxito de su publicación, no sólo alude a cuestiones tales como la comodidad de su manejo o el precio, incluso a la incorporación de ciertas novedades, sino, sobre todo, el mantenimiento de la garantía académica:

El D[iccionario]M[anual] reproduce todo el contenido del diccionario mayor, exceptuando las etimologías y todas las voces y acepciones que en este último llevan las marcas de anticuadas o desusadas.

Además de este contenido "académico", y reemplazando al contingente de las voces y acepciones reputadas fuera de uso, el $D M$ ofrece una información lexicográfica suplementaria nítidamente distinguible para el lector por medio de una señalización que diferencia bien lo "académico" (es decir, lo que es reproducción del D[iccionario] C[omún]) y lo "no académico" (la aportación propia del $D M$ ). Este último sector está constituido por dos subsectores. El primero es el de los "regionalismos, así de España como de América" y "muchas otras voces comunes o técnicas que no hay motivo para censurar, pero que la Academia no quiere acoger en su Diccionario general, fundada las más veces, en que son voces demasiado recientes y no puede presumirse si llegarán a arraigar en el idioma" (Academia, 1927: VIII). Un segundo subsector es el de "los vocablos incorrectos y los extranjerismos que con más frecuencia se usan", con indicación de la "expresión propiamente española que debe sustituirlos"

Por tanto, podríamos deducir de lo anterior que en un "diccionario académico", como es el Diccionario manual e ilustrado, hay información académica, propiamente dicha (la que es reproducción de la del $D R A E$ ), e información no académica, la que se incorpora sin estar presente en el DRAE, como los regionalismos, las voces muy recientes, los vocablos considerados incorrectos por la Academia y

${ }^{3}$ En el prólogo del Diccionario de la lengua castellana, por la Academia Española, compendiado por don Cristóval Pla y Torres, profesor de Lengua Castellana, etc., Librería de B. Cormon y Blanc, Paris, 1826, leemos lo siguiente: "Será muy útil, particularmente para los jóvenes Americanos y Españoles que empiezan sus estudios, debiendo, como parece regular, principiarlos por el de la lengua nativa”.

${ }^{4}$ M. Seco, "La otra voz de la Academia Española. Notas sobre el Diccionario Manual", en Estudios de lexicografía española, Gredos, Madrid, 2003, pp. 337-350 (publicado en Hispanic Linguistic Studies in Honour of F. Hodcroft, Oxford, 1993, pp. 153-169).

${ }^{5}$ Ibid., pp. 338-339. El subrayado es mío. 
los extranjerismos. La información no académica (voces y acepciones) va precedida por un corchete en el Diccionario manual; por ejemplo, la voz "[ranking”, o la acepción "[Poner nervioso" (s.v. enervar en DM 1989). Posteriores ediciones del DRAE registraron algunos de estos usos neológicos, y se introdujo el recurso de la letra cursiva para indicar su carácter de extranjerismos crudos; así, la acepción nueva de enervar se incorpora en la vigésima primera edición del DRAE (1992), y en la vigésima segunda edición (2001) se registra ranking. Sin embargo, nos queda la duda de saber si los lemas en cursiva del DRAE y la microestructura de estos artículos habrá de considerarse, o no, contenido académico. Por otra parte, sí parece que podría atribuírsele (o pudo habérsele atribuido) autoridad académica a un diccionario deficiente desde la perspectiva didáctica como el Diccionario escolar de la lengua española (1996) de la Real Academia, pues registra parcialmente la nomenclatura del DRAE y parcialmente también su microestructura. El Diccionario del estudiante (2005), por el contrario, un correcto diccionario didáctico, no ostentaría esta autoridad académica, pues no sólo da entrada a palabras que no registra el DRAE, sino que suprime acepciones y modifica o adapta definiciones de acuerdo con las capacidades de los destinatarios; es decir, prioriza el carácter didáctico al mantenimiento de la condición de académico.

Veamos, para ilustrarlo, en qué medida son poseedores de la "garantía académica" los propios diccionarios académicos. La 21 edición del DRAE (1992), por ejemplo, proporciona para la voz transexual la siguiente información:

transexual. adj. Dícese de la persona que mediante tratamiento hormonal e intervención quirúrgica adquiere los caracteres sexuales del sexo opuesto. Ú. t. c. s.

Las dos ediciones que se publicaron del Diccionario escolar (RAE, 1996 y 1997) reprodujeron, literalmente, el artículo anterior. En la $22^{a}$ edición del DRAE (2001) se introduce una nueva acepción:

transexual. 1. adj. Dicho de una persona: Que se siente del otro sexo, y adopta sus atuendos y comportamientos. U. t. c. s. 2. adj. Dicho de una persona: Que mediante tratamiento hormonal e intervención quirúrgica adquiere los caracteres sexuales del sexo opuesto. U. t. c. s.

En la $23^{\text {a }}$ edición del $D R A E^{6}$ aparece una nueva acepción, la $1^{\text {a }}$, aunque no había enmienda en la edición en línea que se ofrecía como avance:

${ }^{6}$ Aunque en una primera fase de esta investigación trabajamos con la versión en línea de la $23^{\mathrm{a}}$ edición del $D R A E$, que se anunciaba como un avance de la que sería la definitiva, una vez que se publicó en soporte papel detectamos la existencia 
transexual. (De trans-y sexual). adj. 1. Perteneciente o relativo al cambio de sexo. Cirugía transexual. || 2. Dicho de una persona: Que se siente del otro sexo, y adopta sus atuendos y comportamientos. U. t. c. s. || 3. Dicho de una persona: Que mediante tratamiento hormonal e intervención quirúrgica adquiere los caracteres sexuales del sexo opuesto. U. t. c. s.

El Diccionario esencial de la lengua española (RAE, 2006) transcribe, también, el contenido de la $22^{\mathrm{a}}$, con una mínima variación en la situación de la información gramatical, después y antes del número que introduce a la acepción:

transexual. ADJ. 1. Dicho de una persona: Que se siente del otro sexo, y adopta sus atuendos y comportamientos. U. t. c. s. || 2. Dicho de una persona: Que mediante tratamiento hormonal e intervención quirúrgica adquiere los caracteres sexuales del sexo opuesto. U. t. c. s.

A la vista de estas relaciones, se concluye que el Diccionario escolar presentaría la propiedad de ser "académico" en la medida en que compartía su contenido con la $21^{a}$ edición del DRAE, lo mismo que el Esencial, cuyo diccionario de partida era la $22^{a}$ edición. No así el Diccionario del estudiante (RAE, 2005), que se aleja, en buena medida, de la $22^{a}$ edición del DRAE (la de 2001), pues propone una nueva redacción en la que incluye las dos acepciones de los diccionarios anteriores, proporciona información gramatical adicional e incluye un ejemplo de uso:

transexual. adj. Dicho de persona: Que se siente del sexo opuesto, viste y se comporta en consecuencia, y aspira a adquirir o ha adquirido los caracteres físicos correspondientes mediante tratamiento hormonal o intervención quirúrgica. Tb. m. y f. La ley reconoce el derecho de los transexuales al cambio legal de nombre.

La situación se presenta ciertamente heterogénea: hay diccionarios académicos que recogen parte del contenido del DRAE (como el Escolar), otros que lo superan, o que lo superaron (el Diccionario manualy el Esencial), y otros que lo modifican (el Diccionario del estudiante, por ejemplo). Ante este panorama, cabe plantearse qué criterio habrá de prevalecer y, si el denominado "contenido académico" justifica, a tenor de la realidad del actual DRAE, su prioridad frente a las propuestas de adaptación de los modernos diccionarios a las

de un gran número de discordancias, incluso entre artículos que en la versión en línea aparecían como enmendados; tuvimos, pues, que revisar las referencias que habíamos realizado: ahora todas se refieren a la edición impresa. No hay coincidencia, por ejemplo, entre las entradas dadas para bacán, ni entre la de didáctico, ca, de la que se dice que fue enmendada; la propia voz diccionario, en su primera acepción, presenta notables diferencias entre las dos versiones. 
necesidades y a las destrezas de determinados grupos de usuarios, esto es, a potenciar su carácter "didáctico”.

\section{Lo didáctico}

Un recorrido por la historia de la lexicografía española revelaría que la Real Academia Española no se propuso nunca elaborar un diccionario escolar o didáctico; sí lo hizo para realizar un manual, "si conviene publicarlo" (Estatutos de 1848, estatuto 52), o para la elaboración de compendios "acomodados a las facultades e inteligencia de toda clase de personas" (Estatutos de 1859, Artículo II y Estatutos de 1977, art. $\left.2^{\circ}\right)$. En los Estatutos de 1993 se crea el Instituto de Lexicografía, en el que se integra el Seminario de Lexicografía, con dos órganos de trabajo: "uno para realizar el Diccionario Histórico de la Lengua y otro para atender al léxico moderno, a las necesidades del Diccionario de uso y de otros Diccionarios que la Academia decida elaborar".

Se podría entender que la preocupación por "lo didáctico" de la Real Academia pudiera estar implícita en los artículos de los Estatutos señalados anteriormente; sin embargo, entendemos que no existía tal interés, pues de haberlo se habría procedido con similar claridad con que se expresa esta intención en el caso de la Gramática. Así, en los Estatutos de 1859, en su artículo III, se dice lo siguiente:

Siendo la Gramática de la Academia texto obligatorio y único en las escuelas de enseñanza pública, por virtud del artículo 88 de la ley de 9 de Setiembre de 1857, procurará esta Corporación que, así la Gramática como su Compendio y Epítome, vayan acomodándose a la índole de cada período de la enseñanza, y correspondan a lo que exige el estado actual de los conocimientos filológicos y gramaticales en las naciones más adelantadas de Europa.

Por esa razón, llama mucho la atención que en los últimos años apareciese una incipiente preocupación académica por "lo didáctico" justificada por un inexistente mandato estatutario, como aparece en el prólogo del Diccionario escolar de la Real Academia Española, que más adelante comentaremos.

Lo cierto es que, como se reclamaba para la Gramática y su Compendio, también el Diccionario merecía cierto acomodo "a la índole de cada período de la enseñanza”. En esta línea trabajaron algunos lexicógrafos, primero de forma individual, luego en equipo, hasta ir conformando una nueva orientación en la ciencia lexicográfica: la lexicografía didáctica. Y la Academia también parece haber mostrado cierto interés por incorporarse a esta parcela de la lexicografía: la propia evolución del sentido de la voz didáctico en su Diccionario es una 
buena muestra, desde que apareciera como lema por primera vez en el Suplemento de la $4^{\mathrm{a}}$ edición $(1803)^{7}$ hasta hoy ${ }^{8}$. Y esta preocupación por elaborar definiciones adecuadas al sentido que nos interesa y proporcionar, incluso, ejemplos de uso relacionados con temas lexicográficos puede entenderse como una prueba de cierta orientación de la Institución hacia el didactismo que se le demanda.

\section{PANORAMA DE LA LEXICOGRAFía ACADÉMICA}

Muy didáctico sería, para empezar, que la Academia determine con claridad los objetivos de cada una de sus obras lexicográficas, pues tal ausencia da lugar a un panorama ciertamente confuso.

Se podría, por ejemplo, presentar la producción lexicográfica académica a partir de la distinción que establece dos grandes tipos de repertorios atendiendo a sus finalidades: diccionarios lingüísticos y diccionarios sociales. Con una particular interpretación de la clasificación de Luis Fernando $\operatorname{Lara}^{9}$ y, con un planteamiento muy próximo al suyo, podríamos distinguir entre diccionarios que tienen exclusivamente una finalidad filológica y que, en consecuencia, dan respuestas a dudas concretas que puede plantear ocasionalmente cualquier usuario sobre el origen, la variación, las equivalencias, incluso cuestiones de normatividad, y diccionarios que son objeto de una consulta más sostenida en la medida en que sus funciones descodificadoras y codificadoras son prioritarias, aunque puedan proporcionar otras. Los primeros, los diccionarios lingüísticos, no son textos cerrados y su contenido no tiene por qué constituir una estructura; en estos repertorios no cabe hablar de circularidad ni de pistas perdidas, y su microestructura es tan variable como variada es su finalidad: serían, por ejemplo, los diccionarios etimológicos, los de sinónimos, los dialectales e, incluso, los normativos o de dudas. Los otros, los diccionarios sociales, sí son (o han de ser) textos cerrados y autónomos, y cumplen con funciones de índole general, descodificadoras y codificadoras. En este grupo entrarían los diccionarios generales, los de uso, los compendiados y, por supuesto, los didácticos o escolares.

${ }^{7}$ didáctico, ca. adj. Lo mismo que DIDASCÁLICO [=Lo que es propio y a propósito para la enseñanza].

${ }^{8}$ La $2^{\mathrm{a}}$ acepción del DRAE $23^{\mathrm{a}}$ edición dice de didáctico lo siguiente: "Propio, adecuado o con buenas condiciones para enseñar o instruir. Un método, un profesor muy didáctico". Sentido próximo al de pedagógico ("Expuesto con claridad y que sirve para educar o enseñar"), y al de escolar, "Dicho de un instrumento educativo: Pensado, en su contenido y en su metodología, para facilitar su comprensión a los alumnos. Diccionario, enciclopedia escolar" (s.v. escolar ${ }^{2}, 23^{\mathrm{a}}$ ed., $2^{\mathrm{a}}$ ac.).

${ }^{9}$ Véase "Por una redefinición de la lexicografía hispánica", NRFH, 44 (1996), pp. 353-355. 
La producción académica, siguiendo esta clasificación, estaría configurada como sigue:

Diccionarios lingüísticos

Diccionario histórico (1933-1936; 1960-1996).

Diccionario panhispánico de dudas (2005).

Diccionario de americanismos (2010).

Diccionarios sociales

Diccionario de Autoridades (1726-1739).

Diccionario de la lengua española [DRAE] ( $1^{\mathrm{a}} \mathrm{ed} ., 1780 ; 22^{\mathrm{a}} \mathrm{ed} ., 2001$; $23^{\mathrm{a}}$ ed., 2014).

Diccionarios manuales, compendiados o de uso Diccionario manual e ilustrado de la lengua española ( $1^{\mathrm{a}} \mathrm{ed} ., 1927$; $2^{\text {a }}$ ed., 1950; $3^{\mathrm{a}}$ ed., 1983-1985; $4^{\mathrm{a}}$ ed., 1989).

Diccionario esencial de la lengua española (2006).

Diccionarios didácticos

Diccionario escolar (1 ${ }^{\mathrm{a}}$ ed., 1996; $2^{\mathrm{a}}$ ed., 1997).

Diccionario del estudiante ( $1^{\mathrm{a}}$ ed., 2005; $2^{\mathrm{a}}$ ed., 2011).

Diccionario práctico del estudiante ( $1^{\mathrm{a}}$ ed., 2007; $2^{\mathrm{a}}$ ed., 2012).

Diccionario básico de la lengua española (SM-RAE, 2014).

\section{UNA APROXIMACIÓN CRÍTICA A LOS DICGIONARIOS ACADÉMICOS}

Los diccionarios académicos han sido estudiados y reseñados en numerosas ocasiones, y es extensa la bibliografía de crítica lexicográfica relacionada con ellos, sobre todo con los diccionarios sociales de carácter general, como el Dicc. Aut. y el DRAE. Sin embargo, las referencias a los restantes repertorios (manuales, compendiados y didácticos) es menor, bastante dispersa y heterogénea, por lo que puede resultar de interés hacer una presentación crítica del panorama de estos diccionarios utilizando criterios similares de valoración.

Diccionario manual e ilustrado de la lengua española $(D M I L E)^{10}$

Aspectos generales. Se han publicado del DMILE cuatro ediciones: la primera en 1927, la segunda en 1950, la tercera entre 1983 y 1985 y la cuarta en 1989. Su contenido está basado en el DRAE; para la edición que manejamos para este trabajo, la $4^{\mathrm{a}}$, se partió de la $20^{\mathrm{a}}$ edición, la de 1984.

Equipo responsable. Hay un equipo responsable de su elaboración con dos colaboradores y un auxiliar. Fue coordinado por Alonso Zamora Vicente.

${ }^{10}$ Espasa, Madrid, 1927, $1^{\text {a }}$ ed.; 1989, $4^{\text {a }}$ ed. 
Origen y contenido. Aunque se considera una obra compendiada, su macroestructura está próxima a la del DRAE, unos 83000 artículos. Téngase en cuenta que se han suprimido voces anticuadas y poco usadas, pero se incluyó un buen número de entradas nuevas (extranjerismos y neologismos): es, pues, un resumen a la vez que un suplemento. En el tramo b-balanza, que cuenta con 311 voces en DRAE, hay 292 entradas en el DMILE.

Función y destinatarios. Como compendio del DRAE, pues así se le considera, el DMILE debería tener una función divulgativa, para un público general, sin especificar; si bien, por su enorme difusión, por su tamaño y el precio de las dos primeras ediciones, sobre todo, pudiera pensarse que aspiraba a cumplir una función pedagógica o didáctica, por lo que hay autores que lo consideran un diccionario "de uso" en el ámbito pedagógico.

Valoración. Más que un diccionario de uso para el ámbito pedagógico, el DMILE es una obra de transición entre las ediciones $19^{\mathrm{a}}$ y $20^{\mathrm{a}}$ (1984 y 1992) del DRAE, pues no existe ningún rasgo que nos permita reconocer su carácter didáctico. Sí podría considerarse como un diccionario "de uso" en la medida en que se aligera la obra al suprimir voces y acepciones anticuadas; aunque, al mismo tiempo, se introduce un buen número de voces "aún no incluidas en el Diccionario general", con la idea, suponemos, de plantear si procedía su incorporación definitiva en él. Estas voces nuevas van precedidas por un corchete ([), y otros "usos incorrectos, barbarismos, etc." se marcan con un asterisco. Así, de las 292 entradas que hay en el tramo b-balanza, 36 van precedidas del corchete y tres con asterisco, pero sólo pasaron al DRAE tres de las precedidas por corchetes y ninguna de las marcadas con asterisco.

A la vista de estos datos no parece que haya compensado el esfuerzo por utilizar el DMILE como banco de pruebas -como parece haber sido una de sus funciones- antes de decidir la definitiva conformación del DRAE.

\section{Diccionario esencial de la lengua española ${ }^{11}$}

Aspectos generales. El Esencial apareció en 2006, y es compendio de la $22^{\mathrm{a}}$ edición (2001) del DRAE. Del mismo modo que la nomenclatura del $D M I L E$ recoge el léxico común del $D R A E$, pero sin arcaísmos, éste pretende ser un amplio adelanto de los contenidos que registrará la edición siguiente del Diccionario usual.

Equipo responsable. Hay un equipo de redacción que asesora Manuel Seco y coordina Rafael Rodríguez Marín.

11 Espasa, Madrid, 2006. 
Origen y contenido. Responde este diccionario al mismo planteamiento de la Academia de ofrecer un resumen y un suplemento de la $22^{\mathrm{a}}$ edición del $D R A E$, y utiliza además, según se afirma, otras fuentes documentales como el CREA y el Diccionario del español actual (DEA) de M. Seco [dir.]. Registra en torno a las 44000 entradas. En el tramo b-balanza hay 180 voces.

Función y destinatario. Según el Prólogo y otra documentación de la Academia, el Diccionario esencial tiene carácter divulgativo, pues pone la tarea lexicográfica y normativa de las academias al alcance del gran público y pretende ser el diccionario de cabecera de todos los usuarios, es decir, ofrecer a los hispanohablantes una versión útil, sencilla y actualizada del DRAE.

Valoración. No presenta este repertorio las características de un buen diccionario de uso: microestructura con escasa información, ausencia de ejemplos y algunas novedades léxicas que no aparecen caracterizadas ni como regionalismos ni como vulgarismos. Algunas de ellas, sorprendentemente, están ahí sin que se pueda investigar su origen, pues no figuran en ningún otro diccionario anterior, ni han tenido continuidad en repertorios posteriores; así, en el tramo b-balanza encontramos algunas como babaero (Filip. Dicho de un hombre: mujeriego), bacanora ( $M x$. Bebida alcohólica...), bagayero (Á. Río Plata. Contrabandista), bagayo (Á. Río Plata. Mujer muy fea), bailejo (Á. Andes. llana). En esta ocasión, no se indica, como sí hacía el DMILE, el carácter provisional de estas voces ausentes del DRAE.

\section{Diccionario escolar de la Real Academia Española ${ }^{12}$}

Aspectos generales. Este diccionario se elabora -según leemos en su Preámbulo- para cumplir "un mandato estatutario" de la Real Academia Española para adaptar su Diccionario al uso escolar. Trata así -según se afirma- de "familiarizar con su repertorio léxico a los hispanohablantes más jóvenes, que tendrán que encargarse de forjar el español del siglo Xxi".

Equipo responsable. No hay equipo responsable de su elaboración.

Origen y contenido. Corpus de unos 33000 artículos, según se informa en el Preámbulo, elaborado a partir de la $21^{\text {a }}$ edición (1992) del $D R A E$. En el tramo b-balanza hay 115 entradas.

Función y destinatarios. Su finalidad es didáctica, según informa la Academia, y se destina a los alumnos de educación secundaria.

Valoración. Llama mucho la atención que estando ausente la preocupación didáctica en toda la documentación académica, en el Preámbulo de este Diccionario escolar se afirmase que su publicación

${ }^{12}$ Espasa, Madrid, 1996, 1a $; 1997,2^{\text {a }}$ ed. 
atendía a un requerimiento contenido en los Estatutos de la Institución:

Cumpliendo un mandato estatutario, la Real Academia Española ha decidido adaptar su Diccionario al uso escolar. Trata así de familiarizar con su repertorio léxico a los hispanohablantes más jóvenes, que tendrán que encargarse de forjar el español del siglo xxi (Preámbulo, p. vii).

Falsa afirmación que sólo cabría entenderla como un reclamo con una finalidad meramente comercial, pues ni estaba previsto en los Estatutos tal mandato ni el mal denominado "diccionario escolar" fue objeto de ninguna adaptación al uso escolar. La Lexicografía es "una actividad investigadora y didáctica"13 y el diccionario es una obra de una indiscutible naturaleza didáctica ${ }^{14}$, pero esto no justifica que nos despreocupemos de asegurar ese carácter didáctico de la ciencia y a su objeto; es más, esta certeza habrá de comprometernos aún más a promover la investigación lexicográfica en esta línea y en la elaboración de diccionarios más adecuados a las necesidades y a las destrezas de los destinatarios.

La segunda edición, que se promete "renovada", no introduce ninguna novedad que merezca señalarse ni que mejore la calidad de este deficiente repertorio.

\section{Diccionario del estudiante ${ }^{15}$}

Aspectos generales. Según se informa en las páginas preliminares de la obra, es éste un diccionario de nueva planta elaborado sobre la base de un banco de datos léxicos extraído de los libros de texto y de consulta utilizados en los sistemas educativos de España y de América, con el respaldo añadido de los ricos archivos lingüísticos de las Academias, cada una de las cuales ha cuidado lo relativo a su área lingüística. Es preciso aclarar que en los créditos de este repertorio no figura la Asociación de Academias de la Lengua Española, aunque su participación se declara en las páginas preliminares de la obra.

Equipo responsable. Cuenta con un equipo de redacción que asesoró Manuel Seco y coordinó Elena Zamora.

13 Manuel Seco, "El «contorno» en la definición lexicográfica", en Estudios de lexicografía española, $2^{a}$ ed., Gredos, Madrid, 2003, p. 47. Publicado inicialmente en Homenaje a Samuel Gili Gaya (in memoriam), Biblograf, Barcelona, 1979, pp. 183-191.

14 M. Alvar EzQuerra, "Función del diccionario en la enseñanza de la lengua", en Lexicografia descriptiva, Biblograf, Barcelona, 1993, p. 167.

15 Real Academia Española-Santillana, Madrid, 2005; 2a ed., 2011. 
Origen y contenido. Como se indicó más arriba, es un diccionario de nueva planta cuya macroestructura está en torno a las 40000 entradas. En el tramo b-balanza hay 114, entre ellas 5 son voces americanas.

Función y destinatarios. Su finalidad es didáctica, pues su objetivo es "introducir a los alumnos de secundaria [12 a 16 años] en el maravilloso mundo de la palabra y guiarlos en el conocimiento de nuestro idioma”, según las páginas preliminares.

Valoración. Estamos, sin duda, ante una obra novedosa, muy distinta de las que hasta ahora la Real Academia nos viene ofreciendo: "Hay un trabajo lexicográfico serio y aplicado con coherencia", opinión que compartimos plenamente con J. Martínez de Sousa ${ }^{16}$. Efectivamente, está claro que los elaboradores siguieron las indicaciones de una planta muy bien pensada que dio lugar a una microestructura con abundante información y numerosos ejemplos de uso reales. Habría, sin embargo, que hacer algunos comentarios sobre lo que podrían ser deficiencias; por una parte, la falta de información etimológica, tan importante para los estudiantes de estos niveles de la educación, y la confusión que se introduce al proponer adaptaciones de algunas voces extranjeras; así, por ejemplo, se recomiendan las formas campin, ranquin (y sus plurales cámpines y ránquines) en los artículos camping y ranking, lematizadas en cursiva como tales palabras extranjeras. El consultante podría plantearse, como nos planteamos nosotros, cómo entender estas recomendaciones, pues las adaptaciones en cuestión no aparecen como entradas y, en cierto modo, además de la incongruencia, su presencia provoca un problema de pistas perdidas en el diccionario. Llaman la atención, por otra parte, estas contradicciones no resueltas por la Real Academia en un diccionario, sin duda, académico.

\section{Diccionario práctico del estudiante ${ }^{17}$}

Aspectos generales. El Diccionario práctico del estudiante se basa en el Diccionario del estudiante, y su menor tamaño se consigue por la reducción de la nomenclatura; en la microestructura se suprimen o acortan notablemente los ejemplos y otras informaciones. Aunque se afirma que es "versión especialmente preparada para Hispanoamérica del Diccionario del estudiante", no hemos observado diferencias notables en relación con la obra de partida.

16 "La Academia vuelve al colegio", La Voz de Galicia, A Coruña, 2 de octubre de 2005.

17 Real Academia Española-Asociación de Academias de la Lengua Española, Madrid, $1^{\text {a }}$ ed., 2007; $2^{\text {a }}$ ed., 2012. 
Equipo responsable. Tiene el mismo equipo de redacción que el Diccionario del estudiante.

Origen y contenido. Procede, como dijimos, del Diccionario del estudiante, $\mathrm{y}$, aunque en las páginas preliminares se indica que contiene unas 30000 palabras, nuestros cálculos nos dan en torno a las 20000. En el tramo b-balanza hay 62 entradas, de las que tres son americanismos, por lo que la proporción de voces americanas no parece mayor que la del diccionario de partida; en consecuencia, no parece justificada la precisión que leemos en la página xi: "El Diccionario práctico del estudiante es versión especialmente preparada para Hispanoamérica del Diccionario del Estudiante de la Real Academia española”.

Función y destinatarios. Finalidad didáctica, y, como el anterior, con el objetivo de "introducir a los alumnos en el maravilloso mundo de la palabra y guiarlos en el conocimiento de nuestro idioma”. Se cuidan de no utilizar la denominación de la etapa de los alumnos a los que se destina (la "secundaria" en el del Estudiante), pues puede no coincidir con los sistemas educativos de los distintos países de Hispanoamérica.

En la Presentación de este diccionario puede leerse que se dirige a los alumnos de institutos y colegios de los países hispanohablantes, y que surgió por la convicción de las Academias de que nuestro idioma no disponía aún de un diccionario de calidad destinado a los niveles medios de la enseñanza. De nuevo, otra información que no es totalmente veraz, pues desde 1982 hay diccionarios didácticos integrales de solvencia para estos niveles en México, y, desde el 2003, en Cuba. Más tarde su publicaron otros, también adaptados a cada modalidad nacional del español, en Colombia, desde el 2008, en Puerto Rico y en Argentina, desde el 2009, y en Chile, desde 2010 ${ }^{18}$.

Valoración. Más deficiente que el Diccionario del estudiante, al que no aporta nada nuevo, por más que se presente como diccionario diferenciado y destinado a estudiantes de Hispanoamérica.

Diccionario básico de la lengua española. Primaria ${ }^{19}$

Aspectos generales. El Diccionario básico de la lengua española. Primaria es un repertorio renovado y actualizado a partir de la undécima edición del Diccionario básico de primaria (SM, 2012), y es el resultado de una afortunada colaboración en la que se suman la probada experiencia en publicaciones didácticas -diccionarios entre otras- de los profesionales de

18 Cf. H. Hernández, "La lexicografía didáctica del español en Hispanoamérica: aspectos teóricos y descriptivos", en Estudios de lingüística española. Homenaje a Manuel Seco, ed. F. Rodríguez, Universidad, Alicante, 2012, pp. 269-296.

19 Real Academia Española-Eds. SM, Madrid, 2014. 
ediciones SM y la amplia tradición lexicográfica de la Real Academia Española. Aspira este Diccionario básico a convertirse en auxiliar de consulta imprescindible de los estudiantes de la educación primaria, etapa decisiva en su formación que, como tal, merece un repertorio léxico de referencia indiscutible que ofrezca las máximas garantías, no sólo por brindar la posibilidad de responder a las muchas dudas de índole lingüística que puedan plantearse en cualquiera de las materias de la etapa, sino por asegurar el adecuado acceso a toda la información que contiene, sin necesidad de tener que incurrir en simplificaciones que le hubieran restado calidad. Y no es fácil conseguir este equilibrio entre accesibilidad y rigor, razón por la que la elaboración de un diccionario de estas características precisa de la necesaria combinación de la pericia en la técnica lexicográfica y los conocimientos didácticos para asegurar la adecuación del producto resultante a la capacidad de comprensión y a las destrezas de los destinatarios.

Equipo responsable. Ha sido elaborado bajo la dirección de José Manuel Blecua Perdices, con un proyecto editorial de Concepción Maldonado González y Yolanda Lozano Ramírez de Arellano. Según se informa más arriba, en su redacción han intervenido dos equipos (más de veinte personas), uno de la Real Academia Española, coordinado por María Ángeles Blanco Izquierdo, y otro de Ediciones SM, que coordinó Yolanda González.

Origen y contenido. Contiene más de 20000 artículos y el punto de partida de su nomenclatura es la $11^{\text {a }}$ edición del Diccionario básico de ediciones SM (2012), el cual se cruzó con un conjunto de cerca de 25000 voces obtenido de las de mayor frecuencia del Corpus del español del siglo XXI (CORPES XXI) de la Real Academia Española. Tras un proceso de revisión y actualización, se suprimieron más de 300 lemas de la nomenclatura del diccionario origen y se incorporaron más de 600 de acuerdo con una serie de criterios, como la frecuencia de uso, la efectiva documentación, la vigencia y, por supuesto, la atención a las exigencias propias de una obra de carácter didáctico. Como diccionarios de contraste se utilizaron el DRAE, el DEA y el DUE.

En este Diccionario básico se estableció un modelo de artículo que, basado en el del diccionario de partida, puede resumirse en el siguiente esquema:

lema / lema (silabeo, si es voz española y polisílaba, con indicación de la sílaba tónica) [categoría gramatical] Definición: Ejemplo $\square$ [Notas: Etimología, Pronunciación. Ortografía. Morfología. Sintaxis. Semántica. Uso $\square$ Sinónimos $\square$ Antónimos $\square$ FAmilia.

El lema se escribe en letra cursiva cuando se trata de un extranjerismo crudo, y sólo se da información sobre la división silábica en las voces incorporadas plenamente al idioma, en donde se destaca, 
además, la sílaba tónica. La categoría gramatical se expresa de forma analítica, entre corchetes y menor cuerpo de letra, sin utilizar abreviaturas.

Función y destinatarios. Está pensado, fundamentalmente, para el nivel básico de la educación primaria, período que abarca los cuatro primeros cursos de la etapa, si bien estos límites hay que entenderlos siempre como orientativos, pues no existe homogeneidad absoluta en cuanto a la madurez, desarrollo intelectual, capacidades y destrezas de los alumnos de estas edades.

Valoración. Hay muchas razones para valorar altamente este nuevo diccionario didáctico que presenta, además, un buen número de ilustraciones, cuadros y esquemas que complementan o amplían el contenido de las definiciones; ilustraciones que no constituyen meros ornamentos, sino que se integran como elementos de la macroestructura (ilustraciones temáticas y colectivas) o de la microestructura (ilustraciones individuales o con dos o tres componentes).

Otra importante novedad es la posibilidad que se ofrece para acceder por medio de la Red. En cada ejemplar del Diccionario básico se proporciona una clave de acceso para consultarlo en línea a través del portal www.smdiccionarios.com, y disponer de una serie de actividades interactivas para trabajar en clase individualmente y en grupo. Se ofrece, pues, la versión digital como un complemento a la versión en papel para que el estudiante pueda consultar fuera del aula su diccionario y aprender de forma lúdica en caso de que deje su libro en el aula. Es, además, un complemento ideal para utilizar en clase al poder proyectarse en una pizarra digital y consultar el significado de las palabras, descargar sus ilustraciones temáticas o trabajar con las más de 400 actividades que se incluyen.

El Diccionario básico de primaria puede renunciar a ostentar el calificativo de "académico" porque esta renuncia lo lleva a merecer la condición de "didáctico"; proceder en el sentido contrario, además de innecesario, hubiera significado desatender una vez más las demandas de los usuarios más necesitados y desasistidos por la práctica lexicográfica durante muchos años.

\section{RELACIONES ENTRE LOS DISTINTOS DICGIONARIOS ACADÉMICOS}

Para determinar las relaciones que existen entre los repertorios académicos, en qué medida unos se basan en los otros, o son deudores de la tradición que algunos van marcando, podrían compararse elementos de su estructura, como el número de entradas y qué voces se lematizan; y, en la microestructura, observar cómo se distribuye la información y analizar semejanzas y diferencias. Veamos, para ilustrarlo, la voz bacán presente en los repertorios académicos recientes: 
La registra por primera vez el DMILE (1927, $1^{\mathrm{a}}$ ed.; 1989, 4ª ed.):

[bacán. m. Cuba. tamal, especie de empanada.

No recogieron la voz ninguno de los siguientes diccionarios académicos, desde la $15^{\mathrm{a}}$ edición (1936) hasta la $21^{\mathrm{a}}$ edición (1992). Sí se mantiene en las distintas ediciones del DMILE (1950, 1983 y 1989).

Aparece en la $22^{\mathrm{a}}$ edición del $D R A E$ (2001), y en la $23^{\mathrm{a}}$, pues no hay enmienda en el avance en línea, pero no con el sentido de 'tamal':

bacán ${ }^{1}$, na. adj. 1. Chile, Col., Cuba y R. Dom. En lenguaje juvenil, muy bueno, estupendo, excelente. || 2. colq. Col. Cubay R. Dom. Dicho de una persona: Muy atractiva.

bacán ${ }^{2}$. m. 1. coloq. Cuba. Hombre mantenido por su esposa o por su amante. 2. Ur. Hombre que costea los gastos de las mujeres con las que mantiene vínculos. $\odot$ m. y f. 3. coloq. Arg., Col. y Ur. Persona adinerada.

El Diccionario del estudiante (2005) registra un solo artículo:

bacán, na. adj. 1. Am. coloq. Estupendo o muy bueno. Que Bolivia me saque del atolladero les parece recontra bacán [C]. 2. Am. coloq. Ricachón (rico o adinerado). Frec. m. y f. Usted anduvo por Chile bien "forrado", hecho un bacán, con una camioneta y hasta un "chofer" [C].

El Esencial (2006) vuelve al planteamiento homonímico iniciado en el DRAE:

bacán ${ }^{1}$, na. ADJ. Á. Caribe. En lenguaje juvenil, muy bueno, estupendo, excelente.

bacán². COM. Á.R. Plata. Persona adinerada.

Muy similar al del Estudiante es el artículo del Práctico (2007):

bacán, na. adj. 1. Am. coloq. Estupendo o muy bueno. Les parece recontra bacán [C]. 2. Am. coloq. Ricachón. Frec. m. y f. Usted anduvo por Chile bien "forrado", hecho un bacán [C].

La voz bacán se registra por primera vez, como se ve, en la lexicografía académica en el DMILE desde su $1^{\text {a }}$ edición en 1927, con marca de provisionalidad ([), tomado, seguramente, de E. Zerolo (Diccionario enciclopédico de la lengua castellana, 1895) que ya le da la localización (Am. Cuba) y de J. Alemany (Diccionario de la lengua española, 1917), con este sentido de 'tamal' (también recoge Alemany el nuevo sentido de 'persona adinerada' para el español de Argentina). Sin embargo, la voz no vuelve a aparecer, como decíamos, con este sentido en 
los restantes diccionarios. No figura como entrada en las siguientes ediciones del $D R A E$ (de la $15^{\mathrm{a}}$ a la $21^{\mathrm{a}}$ ) y reaparece en la $22^{\mathrm{a}}$, esta vez en dos artículos (como adjetivo y como sustantivo), sin registrar el sentido primero y sin proporcionar etimología. El Diccionario esencial (2006) reconoce los dos homónimos y simplifica las acepciones.

Un seguimiento de la evolución del tratamiento de la voz nos revelaría una situación un tanto anárquica e inconexa de los diccionarios académicos: falta de la relación esperada entre el DMILE y el DRAE, entre el DRAEy los repertorios didácticos (bacán no aparece en el Diccionario escolar); aunque sí existen rasgos que denotan cierto grado de parentesco entre el DRAE y el Esencial (que puede considerarse su compendio) y entre el Diccionario del estudiantey el Práctico, que, en realidad, es una mera reducción inorgánica del anterior.

Convendría profundizar en el contenido de la voz, pues está viva en el español americano, como se desprende de las consultas de los corpus académicos y del propio Diccionario de americanismos ${ }^{20}$. En este diccionario encontramos la siguiente información:

bacán.

I.1. m. Cu. Hombre homosexual.

II.1. m. Cu. Hombre mantenido por una mujer.

III.1. m. Cu. Empanada hecha con carne de cerdo, tomate y ají, envuelta en hojas de plátano.

IV.1. m. Ni. Fiesta bulliciosa, generalmente con bebida.

bacán, -na.

I.1. sust/adj. $C u, R D, C o, P e$. juv. Persona agradable, simpática, amable.

2. adj. $C u, E c, P e, C h$, juv. Referido a una persona o cosa, muy buena, estupenda, excelente.

3. $\mathrm{adj} /$ sust. $\mathrm{Cu}, \mathrm{Pe}$, Referido a persona, muy atractiva.

II. (Del genovés bocan).

1. m. y f. $C u, B o, A r, U r$, pop. Persona adinerada.

2. adj. Cu, Ar, Ur. Referido a un lugar, frecuentado por personas adineradas.

3. Cu, Ar. Referido a un objeto, caro, lujoso.

Puede observarse cómo en el Diccionario de americanismos (DA) aparece la acepción que se corresponde con tamal (III.1. m. Cu. Empanada hecha con carne de cerdo, tomate y ají, envuelta en hojas de plátano), que no están presentes las dos acepciones $\left(2^{\mathrm{a}}\right.$ y $\left.3^{\mathrm{a}}\right)$ que para Chile proporciona el $D R A E$ en bacán' ('prepotente, sobrada [una persona]' y 'taquillero') y que, previsiblemente, a pesar de no estar en el Diccionario de americanismos, aparecerán en la $23^{a}$ edición.

${ }^{20}$ Asociación de Academias de la Lengua Española-Perú, Santillana, 2010. 
Tampoco registra el $D A$ la $2^{\mathrm{a}}$ acepción de bacán ${ }^{2}$ ('hombre que costea los gastos de las mujeres con las que mantiene vínculos'). De nuevo, nos asalta una duda: ¿no va a aprovechar la Real Academia Española, como una más de las veintidós academias que constituyen la Asociación de Academias de la Lengua Española, la rica información que registra el $D A$ para mejorar el $D R A E$ en lo relativo a la información sobre el español de América, si es que de verdad aspira a convertirse en un diccionario general?

De estos análisis comparativos también pueden extraerse otras muchas conclusiones, como, por ejemplo, la dudosa validez de la información diatópica, pues es tan heterogénea en los diccionarios de la Academia que no queda más remedio que ponerla en cuestión. Incluso entre aquellos diccionarios que guardan un evidente parentesco, como el DRAE y el Esencial, se observan discordancias en la marcación; así, el DRAE propone las zonas de Chile, Colombia, Cuba y República Dominicana para la primera acepción de bacán $^{1}$, pero el Esencial proporciona la marca "Á. Caribe": por supuesto, no es Chile, precisamente, un territorio caribeño. La $3^{\mathrm{a}}$ acepción de bacán $n^{2}$, "Persona adinerada", se localiza, según el DRAE en Argentina, Colombia y Uruguay; sin embargo, Esencial determina que este uso es propio del Río de la Plata: obviamente, no es Colombia país que se sitúe en esta área del Cono Sur.

Distinta información diatópica proporcionan el Diccionario del estudiantey el Práctico, en los que hay dos tipos de marcas para el español americano: la marca "Am.", voz o acepción de "Uso exclusivo de América, atestiguado al menos en dos países", equivalencia que se da en los preliminares de este diccionario, y la marca "frecAm.", de "Uso frecuente de América, al menos en dos países, no desconocido en España”. Esta solución está en consonancia con la propuesta que en su momento hicimos para el Diccionario Clave: "En zonas del español meridional", por la que optamos antes que proporcionar información errónea, puesto que con los datos que se poseen resulta imposible hacerlo con absoluta precisión. Esta realidad queda aún más patente después de los cotejos que hemos realizado entre el DRAE y el Diccionario de americanismos. Este es el artículo que venimos analizando en el Diccionario Clave:

bacán, -a adj. 1 col. En zonas del español meridional, elegante o de categoría: un hotel bacán. adj./s. 2 col. En zonas del español meridional, que vive sin privaciones y gozando de una buena posición social: Vivía como un bacán. 


\section{Conclusiones}

A pesar de ser el didactismo una característica propia de la lexicografía como disciplina y de los propios diccionarios, la Real Academia Española no ha mostrado esa preocupación que sí se viene observando en la Gramática y en la Ortografía.

Sí hubo iniciativas al margen de la Academia para elaborar diccionarios con finalidad didáctica, aunque tales propuestas se quedaron en simples compendios (abundaron en el siglo XIX y primeras décadas del xx), cuya única adaptación suponía la reducción material e inorgánica de los contenidos del Diccionario académico.

El primer intento de la Academia por producir diccionarios destinados al gran público y con la aspiración de ofrecer un contenido más real y descriptivo se produce en 1927 cuando aparece la primera edición del Diccionario manual e ilustrado de la lengua española. Mucho más tarde, en 2006, se publica el Diccionario esencial de la lengua española, si bien en ninguno de los dos casos se consiguió el objetivo de convertirse en diccionario con finalidad pedagógica, como se prometía en sus prólogos y en la publicidad institucional.

En 1996, la Real Academia publicó el primer diccionario con una clara y firme finalidad didáctica, el Diccionario escolar de la lengua española, aunque en ninguna de sus ediciones responde al estatus que dice poseer. El así denominado "diccionario escolar", aunque muy divulgado, no mereció el reconocimiento de los docentes ni de la crítica lexicográfica científica.

Con la aparición de la primera edición del Diccionario del estudiante en 2005, la Real Academia responde por primera vez a la apuesta de elaborar un verdadero diccionario didáctico y contribuir a la lexicografía didáctica sobreponiendo esta condición a la tradicional preocupación de mantener el "contenido académico". Esta apuesta académica ha tenido continuidad con la elaboración y publicación en 2014 del Diccionario básico de la lengua española de Primaria.

Un análisis conjunto de la producción lexicográfica de la Real Academia revela, al menos en lo que a diccionarios sociales se refiere, la ausencia de un plan global de publicaciones, pues sus diccionarios no constituyen una serie, en la medida en que no están secuenciados y sus relaciones son casuales, cuando no inexistentes.

A pesar de disponer de recursos para elaborar buenos diccionarios sociales, la Real Academia Española parece haber procedido de espaldas a todos ellos: salvo fundamentarse en la tradición de cada uno de los diccionarios usuales, no se ha contado con los resultados de la experiencia de la publicación de repertorios con ciertas novedades (el caso del DMILE), no se ha aprovechado la rica documentación de sus bases de datos (CREA, CORDE, CORPES XXI), ni del trabajo coordinado de la Asociación de Academias (ASALE), pues no 
se ve reflejada en la próxima edición del DRAE la rica información que proporciona el Diccionario de americanismos.

El peso de "lo académico", muy ligado al de autoridad lingüística, ha llevado a la Institución a despreciar la consideración de otras características, como la de "lo didáctico", razón por la que, hasta fechas muy recientes, no existía un repertorio académico que pudiese destinarse a los estudiantes, por más que en sus denominaciones figurase el adjetivo "escolar" o entre sus finalidades se asegurase que su orientación era pedagógica. Hoy hay ejemplos que indican un claro cambio de rumbo, como el caso del Diccionario del estudiante (2005) y, más recientemente, el Diccionario básico de la lengua española (2014).

Humberto Hernández

Universidad de La Laguna 